\title{
NECESSIDADES FORMATIVAS DO PEDAGOGO PARA ATUAÇÃO EM ESPAÇOS NÃO ESCOLARES
}

Training needs of the pedagogue for action in non school spaces

\author{
Edna Nascimento Oliveira Veras \\ Daniel Silas Veras \\ Maria de Jesus Dias de Araújo
}

RESUMO: A presente pesquisa teve por intuito levantar na literatura as principais necessidades formativas dos pedagogos para atuação nas organizações não escolares, dessa forma para obtenção dos dados necessários fez-se um levantamento e leitura crítica sistematizada de publicações contidas em bases de dados como Portal CAPES e Google acadêmico, o período de busca foi principalmente de documentos publicados nos últimos 10 anos. Dessa forma, a revisão foi dividida em quatro itens, sendo que o primeiro tratou da pedagogia como um campo da educação que entre os diversos escopos trata do processo educativo. Já o segundo tópico versou sobre a formação do pedagogo brasileiro, enquanto no terceiro momento tratou-se sobre a atuação desse profissional tanto nos espações escolares quanto nos espaços não escolares, fechando a revisão listou-se e discutiu-se quais são os principais saberes e quais habilidades estão relacionados a esses conhecimentos necessários ao pedagogo para desenvolver efetivamente suas atividades em espaços não escolares. Assim, a presente revisão mostra-se um importante instrumento tanto para instituições formadoras quanto para os acadêmicos que desejam atuar nos variados espaços não escolares.

Palavras-chave: Necessidades formativas. Pedagogo. Espaços não escolares.

\begin{abstract}
This research aimed to making in the literature the main training needs of pedagogues to work in non-school organizations, in order to obtain the necessary data, a systematized survey and critical reading of publications contained in databases such as Portal CAPES and Google academic, the search period was mainly of documents published in the last 10 years, so the review was divided into four items, and the first dealt with pedagogy as a field of education that among the various scopes deals with the educational process. The second topic dealt with the formation of the Brazilian pedagogue, while in the third moment it was dealt with on the performance of this professional both in school spaces and in non-school spaces, closing the review was listed and discussed what are the main knowledge and what abilities are related to the necessary knowledge of the pedagogue to effectively develop their activities in non-school spaces. Thus, the present review is
\end{abstract}


an important instrument for both training institutions and academics who wish to work in various non-school spaces

Keywords: Non-school spaces. Pedagogue. Training needs.

\section{INTRODUÇÃO}

A educação é um dos mais importantes aspectos das sociedades humanas, tendo em vista que ela é que nos leva a busca pelo conhecimento. Para Costa, (2015, p.75) a educação é uma concepção filosófica e/ou científica acerca do conhecimento colocado em prática, assim ela é que nos leva para saber, para fazer, para ser ou para conviver, seja com a natureza ou com os nossos semelhantes (BRANDÃO, 2007). Portanto, podemos considerar que o ensino vai além de apenas transmitir conhecimento, mas ele seria a busca de criar as possibilidades para a sua produção ou construção (FREIRE, 1996).

Como elaboração da cultura humana, a educação e o ensino ocorrem em todos os momentos de nossas vidas, então, esses processos podem ser desenvolvidos tanto em espaços voltados especificamente para esse objetivo, os quais são denominados espaços escolares que são compreendidos por MendesFilho e Vidal (2000) como os espaços adequados para o ensino, no qual são desenvolvidos os programas e currículos intimamente relacionados a distribuição e a utilização dos tempos escolares. Como também podem ser desenvolvidos nos espaços denominados não escolares que, segundo, Brandão (2007) são compreendidos como os lugares da vida e do trabalho, que reúne pessoas e tipos de atividade, onde viver o fazer faz o saber.

Os modelos neoliberais mudaram as relações de trabalho na sociedade contemporânea, principalmente por terem impulsionado uma revolução tecnológica que rompeu ainda mais com os meios de produção de capital anteriores a esse modelo (LEFF, 2008). Diante dessas novas perspectivas, Lemos e Cabral (2015) destacam que a atuação do pedagogo não esteja limitada somente a escola, mas cada vez mais tem-se tido demandas da atuação desse profissional em outros espaços de trabalho, pois sua formação está voltada para o desenvolvimento humano. Tendo em vista que, neste século, diferente dos anteriores o saber em 
relação aos trabalhadores está centrado no intelecto, pois com as inovações tecnológicas observamos que houve a mudança de foco no trabalho (MINARELLI, 1996, apud CERONI, 2006).

$\mathrm{Na}$ contemporaneidade, a exigência de novas competências e habilidades leva a premência das organizações em ter um profissional que possa ajudar a organização, de qualquer segmento, a atingir os seus objetivos e metas organizacionais, neste caso o perfil do pedagogo deve estar em consonância com a organização (CERONI, 2006).

Desse modo, o que nos impulsiona a adentrar nessa temática é identificar e destacar as necessidades formativas que os profissionais desse campo do conhecimento precisam conquistar para romper com a visão de que só podem atuar em atividades docentes, pois apesar de já encontramos alguns trabalhos que tem como foco a atuação em espaços não escolares, poucos são voltados para as necessidades formativas, ou seja, para as competências e habilidades essenciais para efetivar o fazer desse ator social nessas novas esferas sociais.

Então, devemos nos questionar se a formação desse profissional tem atendido as exigências desses novos postos de trabalho, e caso não esteja sendo atendido essas exigências, quais são as principais necessidades formativas do pedagogo para atuar nesses novos postos de trabalho?

Nessa perspectiva, a presente revisão tem por objetivos: Levantar na literatura científica as necessidades formativas do pedagogo para atuar em espaços não escolares (organizações); descrever o processo formativo do pedagogo a partir das diretrizes curriculares para formação profissional da área; diferenciar a atuação do profissional pedagogo em espaços escolares e não escolares e identificar as principais necessidades formativas do pedagogo para atuação em espaços não escolares.

\section{METODOLOGIA}

A abordagem metodológica adotada para a investigação foi a revisão bibliográfica que é uma técnica que auxilia a conhecer e compreender melhor os elementos teóricos que fundamentarão a análise do tema e do objeto de estudo, fundamentando-se apenas em contribuições secundárias (REIS, 2012). 
A pesquisa foi executada através de consulta a bibliografias tornadas públicas, referentes ao tema exposto no projeto de pesquisa. O levantamento bibliográfico foi realizado por meio das publicações veiculadas em livros, teses, dissertações e periódicos científicos disponíveis online, no Portal CAPES, e no Google acadêmico, para a coleta das informações, foram utilizados alguns descritores como: educação, pedagogia, formação, gestão escolar, processo educativo, tendências pedagógicas e espaços não escolares. As referências selecionadas foram principalmente aquelas publicadas nos últimos 10 anos.

A etapa de levantamento das publicações ocorreu no período de 01/08/2017 a 28/11/2017. O refinamento do levantamento foi realizado através da leitura do título e do resumo disponível nas bases de dados, aqueles trabalhos que se encaixaram na temática da pesquisa foram selecionados para a análise e a interpretação das publicações. Após uma análise/leitura criteriosa dos artigos selecionados, os conteúdos foram categorizados e discutidos conforme os objetivos descritos na pesquisa, de modo a facilitar a organização do tipo de estudo. Nessa etapa que se atribui juízo de valor ao material científico analisado, podendo-se fazer uma reflexão dos pontos principais que compõem a temática, as semelhanças e as discordâncias acerca desse material. Os mesmos procedimentos foram utilizados para análise de livros, teses e dissertações.

\section{EDUCAÇÃO: A PEDAGOGIA E OS PROCESSOS EDUCATIVOS}

Segundo Saviani (2014), a educação é a via pela qual ocorre a mediação entre o homem e a ética, entre o homem e a cidadania e entre a ética e a cidadania. Assim, o homem pode compreender sua consciência na dimensão ética e da cidadania de forma a pensar neste fato para sua vida, em termos de direitos e deveres diante dos outros e de toda sociedade.

Nessa perspectiva, consideramos que o ensino deve ser pautado no que Rousseau, Kant e Freire pensaram ser o necessário para a formação do cidadão, que é desenvolver os saberes exigidos pelas demandas do mundo emergente, nesse caso, a capacidade de pensar por si (BARBOSA; ABDIAN, 2013). Para Oliveira e Lima (2016), as demandas emergentes exigem uma prática educativa engajada na luta pela transformação da realidade social. Portanto, deve-se 
desenvolver nos professores o conhecimento de si mesmos e de sua prática e da relação de sua prática além do contexto escolar, mas também com práticas sociais mais amplas.

Para isso, precisamos dos direcionamentos da pedagogia que, no Brasil, pode ser entendida como o campo que toca em um conceito utópico, pois fixa objetivos educacionais com base em valores, os quais dependem de uma mudança geral da sociedade, além da educação, assim como um conceito de ciências da educação, quando está tenta compreender a realidade sócio educacional do brasileiro (GIRALDELLI JR, 2007).

Então, norteados nos conhecimentos gestados na pedagogia é que se estabelecem os processos educativos, esses podem ser compreendidos como espaços e fluxos onde ocorre os processos de ensino e a aprendizagem que são tanto diversos quanto múltiplos (VIANA, 2015). Os processos educativos são norteados por tendências pedagógicas, as quais se relacionam com acontecimentos históricos delineados a partir de movimentos sociais e filosóficos (Rodrigues et al., 2013). Assim esses eventos configuram diferentes concepções de homem e de sociedade e, consequentemente, diferentes pressupostos sobre o papel da escola, aprendizagem, relações professor-aluno, técnicas pedagógicas (LIBÂNEO, 1982).

As tendências pedagógicas podem ser classificadas em: liberais e progressistas. As tendências liberais têm como características a formação para o desempenho de uma função social, sendo que as diferenças de classes são escamoteadas, tendo em vista que essa ideologia prega a igualdade de oportunidades, sem levar em conta a desigualdade de condições. Por outro lado, as tendências progressistas se caracterizam por nortear os fins sociopolíticos da educação, considerando a educação como instrumento de reflexão crítica da educação. Essa corrente defende a transformação da sociedade através da educação (LIBÂNEO, 1982; RODRIGUES et al., 2013).

Quanto ao desenvolvimento de saberes para a transformação social, sabe-se que depende da formação de novos valores, que não se encontram apenas na educação formal, mas na formação para a participação coletiva de pessoas diferentes com metas iguais, podendo estar também na educação não formal (GOHN, 2006).

\section{A FORMAÇÃO DO PROFISSIONAL PEDAGOGO}


Cabral (2012) entende que a formação proposta para o profissional da pedagogia deve ser abrangente e exigir uma nova concepção de educação, de escola, da pedagogia, da docência, da licenciatura, uma nova compreensão que situe esses elementos num contexto mais amplos das práticas sociais construída nos processos de vida real dos homens, com a finalidade de demarcar o caráter sócio histórico desses elementos.

Portanto, a pedagogia como campo de estudo deve ser vista como uma aliada em qualquer área que demande conhecimento pedagógico, ou seja, no processo de desenvolvimento e formação de sujeitos independente do ambiente que eles estejam. São muitas as possibilidades para atuação desse profissional que vão desde organizações sociais a hospitais, e também no desenvolvimento de materiais para a educação à distância, em instituições religiosas e ONGs (BOGORNY, 2015, P.202).

O curso de pedagogia já passou por várias transformações, desde a sua criação em 1939, nessa época a maior parte dos professores eram "leigos", e a educação sofria forte influência da tendência escolanovista. Além disso, buscava-se maiores espaços para estudo e condições de trabalho para o professor (Fiorin; Ferreira, 2013). Inicialmente, o curso de pedagogia para formar o professor funcionava no modelo denominado $3+1$, pois eram necessários três anos de disciplinas que conferiam o grau de bacharel e mais um ano do curso de Didática, essa configuração estabeleceu a dicotomia entre o conteúdo e o método e entre teoria e prática (ARANTES; GEBRAN, 2014)

A partir de 1969 foram estabelecidas as habilitações do pedagogo, a partir do parecer CNE n․ 252, esse profissional pode exercer as funções de: administração escolar, supervisão e inspeção de escolas e sistemas de ensino (Cruz, 2012). Nesse período, a educação tinha por objetivo a produção em massa, homogeneidade e verticalismo, reflexos do taylorismo/ fordismo (Fiorin; Ferreira, 2013).

Já na década de 1970, o curso de pedagogia passa a se configurar como um curso voltado para a formação de professores. Nessa época, ocorre a produção de pesquisas e publicações no campo da educação contra práticas autoritárias e ideológicas no regime militar (Libâneo, 2007). A partir de 1990, ainda há discussões sobre as funções do pedagogo. Começa-se a pensar na atuação desse profissional em ambientes não escolares (FIORIN; FERREIRA, 2013) 
No ano de 1996 é promulgada a lei de diretrizes e bases da educação nacional (LDB) № 9394, que estabeleceu a normatização para as diretrizes curriculares nacionais para o curso de pedagogia (DCN). No ano de 2002, se estabelece as DCN para formação do professor de educação básica. No ano de 2005, as DCN para formação do pedagogo foram enviadas para homologação e, somente no ano de 2006, essas diretrizes foram promulgadas pela resolução CNE/CP no 1 (Arantes; Gebran, 2014). Assim, se estabeleceu o perfil atual do profissional pedagogo, pois este foi traçado pelas Diretrizes Curriculares Nacionais, lançadas em 15 de maio de 2006 (BRASIL, 2006).

Além de instituir as diretrizes, a nova resolução exigiu uma reflexão rigorosa, oportunizando o debate e a tomada de decisões necessárias, pois se sabe que de uma boa e sólida formação de qualidade dos profissionais da educação e de uma boa e sólida gestão da educação dependerão a vida futura de todos que pela escola passarem (FERREIRA, 2006, p. 1343).

Então, as DCN's para formação em Pedagogia estabeleceram complementarmente, também ao desenvolvimento de competências para o ensino nos cursos de nível médio, na modalidade normal; ao ensino na educação profissional na área de serviços e apoio escolar; às atividades de organização e gestão educacionais; e às atividades de produção e difusão do conhecimento científico-tecnológico do campo educacional (SCHEIBE, 2007, p. 44 ).

As Diretrizes também estabeleceram em seu artigo 7, que a licenciatura em Pedagogia deveria ter uma carga horária mínima de 3.200 horas, divididas em 2.800 horas de atividades formativas, 300 horas de estágio supervisionado e 100 horas de atividades teórico-práticas de aprofundamento e áreas específicas, que podem ser desenvolvidas na forma de iniciação científica, de extensão ou monitoria (BRASIL, 2006).

\section{O PEDAGOGO EM ESPAÇOS ESCOLARES E NÃO ESCOLARES}

No espaço escolar que é compreendido como o local onde ocorre o desenvolvimento dos processos de contexto de aprendizagem, os pedagogos são responsáveis por desenvolver os processos educativos, sendo esses entendidos como o conjunto coerente de fatos, circunstâncias e pessoas que acompanham e 
concretizam uma situação de aprendizagem, ou seja, representa as atividades que ocorrem durante o processo de aprendizagem, incluindo os processos de avaliação; os objetivos da aprendizagem e aos motivos que sustentam esses objetivos; referese ao espaço, físico e virtual, simbólico, cultural e político onde a aprendizagem decorre, incluindo a componentes materiais; descreve as estratégias de aprendizagem; e também inclui alunos, professores e os outros atores envolvidos no processo de aprendizagem (FIGUEIREDO, 2016).

Nos espaços não escolares, o pedagogo tem se caracterizado como o profissional responsável em direcionar as práticas de intervenção na Educação NãoFormal, já que sua formação permite um conhecimento amplo sobre o ato de educar (Santos; Santos, 2011). Dessa forma, o trabalho pedagógico fora dos ambientes escolares traz uma inovação na atuação do pedagogo permitindo perspectiva na construção dos valores da cooperação, da solidariedade e da emancipação humana, principalmente devido a esses profissionais passarem a exercer sua atividade profissional em ambientes não escolares diversificados, por possuírem a atividade pedagógica como base para o desempenho de sua atividade laboral (LEMOS; CABRAL, 2015).

Portanto, a educação não-formal capacita os indivíduos a se tornarem cidadãos do mundo. No mundo, sua finalidade é abrir janelas de conhecimento sobre o que circunda os indivíduos e suas relações sociais. Os objetivos dessa educação não são dados a priori, eles se constroem no processo interativo, gerando um processo educativo (JACOBUCCl et al., 2013).

Esses novos cenários sociais para a atuação do pedagogo foram criados pelo modelo neoliberal, ligada aos fenômenos da industrialização, da migração campocidade e, principalmente, às crescentes e recursivas crises por que passaram (e ainda passam) setores da economia, gerando entre outros fenômenos a precarização nas relações de trabalho (MOURA; ZUCCHETTI, 2014). Esse processo, segundo Lemos e Cabral (2015), leva o egresso de pedagogia a não se prender somente à atuação como docente, mas abre uma gama de possibilidades de campos de atuação relativamente mais novos e variados como empresas, hospitais ou instituições socioeducativas, nas quais se exigem uma boa qualificação dos empregados para atuarem dentro dessas organizações.

Devemos considerar, principalmente, que essas organizações, muitas vezes, são a vanguarda do desenvolvimento de novas tecnologias da informação que, para 
Streck (2012), causa uma revolução no campo cognitivo, fazendo um mudança na reconfiguração, tanto nos espaços quanto nos tempos de ensinar e aprender levando a mudanças no papel do professor.

Então, como uma visão mais interdisciplinar do conhecimento está ganhando espaço, e os pedagogos também estão sendo requisitados a atuar em diferentes instituições, entre as quais podemos citar: os setores de recursos humanos de empresas, podendo aprimorar os processos da empresa por meio da valorização do conhecimento e da aprendizagem, trabalhando para a instalação de uma cultura de formação continuada e de constante busca de informações e conhecimento com a finalidade de melhorar a qualidade do atendimento dos clientes e o relacionamento com os funcionários (BOGORNY, 2015, p. 203).

Além da área de recursos humanos também houve maior inserção desse profissional na instituição hospitalar, na qual seu objetivo é assistir a criança e ao adolescente hospitalizado em seu desenvolvimento emocional, afetivo e cognitivo. Em linhas gerais: a) agenciar a integração entre a criança, a família, a escola e o hospital, tornando os traumas da internação mais brandos, numa proposta de amenizar a possível desmotivação e estresse ocasionados pela internação; b) propiciar relação e proximidade entre a nova vivência da criança e a do adolescente no hospital com sua rotina diária, anterior ao internamento; e c) possibilitar à criança hospitalizada o acesso à educação, mesmo se encontrando em ambiente hospitalar. Ao desenvolver atividades nesse setor, o trabalho pedagógico assume papel transformador das relações sociais dentro do hospital, transformando esse ambiente triste e, muitas vezes, desconfortante em um local mais descontraído e harmonioso (AQUINO; SARAIVA; BRAÚNA, 2012).

\section{O PEDAGOGO E SUAS NECESSIDADES FORMATIVAS PARA ATUAR EM ESPAÇOS NÃO ESCOLARES}

As modificações na função do professor (pedagogo) exige o domínio de saberes e habilidades, além daquelas de gestão dos processos pedagógicos necessários a aprendizagem, assim, Prado, Machado e Cardoso (2013) colocam que esses profissionais devem se especializar profissionalmente tendo em vista o ser humano e as necessidades das organizações, mas, sempre estando cientes de que estão gerindo pessoas e que a mesma tem necessidades específicas e devem 
aprimorá-las para um rendimento satisfatório para ambas as partes.

Considerando o exposto, dentre as necessidades formativas para atuação em espaços não escolares, verifica-se a necessidade do desenvolvimento de saberes que dependem de habilidades intelectuais, aplicativas e socioafetivas, essas categorias são necessárias para atuações em todos os campos de atuação do pedagogo (SANTOS E GUIMARÃES, 2015; SEVERO, 2015).

A atuação desse profissional deve estar pautada em habilidades e em saberes (SEVERO, 2015). Os saberes são os conhecimentos produzidos diante da experiência do ser em diferentes ambientes de socialização da formação profissional e da vida (PENNA, 2012). Relativo aos saberes, os trabalhos de Severo (2015) e Santos e Guimarães (2015) sumarizam como saberes necessário a atuação em espaços não escolares:

- Conhecimento em perspectivas analíticas diversificadas para formação de conceitos básicos sobre o processo educativo;

- Conhecimentos relacionados a metodologia da investigação educativa;

- Conhecimentos sobre didática.

- Conhecimentos sobre gestão educacional e elaboração de projetos socioeducativos;

A capacidade de formação de conceitos básicos sobre os processos educativos e de concepções mais complexas do fenômeno educativo em suas diferentes dimensões é fundamental, uma vez que as manifestações educativas escolares surgem de processos formativos da educação como prática social (SEVERO, 2015).

Quanto aos processos de pesquisa em educação, eles são importantes, pois, invariavelmente, a pesquisa é um elemento que estabelece uma racionalidade prática que requer um intercâmbio entre a teoria e prática em um processo de reflexão-ação criados em contextos e com a participação de outros sujeitos na atividade (SEVERO, 2015). Ademais, a pesquisa permite a construção de uma fundamentação teórica e metodológica que permitam o questionamento e a discussão do campo de atuação em que o pedagogo está inserido, tornando-o um sujeito ativo e interativo com as demais instituições e com o próprio conhecimento (KIRSCH;SOFFNER, 2015).

Em relação à didática, se pensa nela como o campo que proverá os referenciais teórico-metodológicos que nortearão as práticas educativas da 
concepção até a avaliação, a partir de uma reflexão multidimensional e crítica sobre a relação pedagógica entre ensino, aprendizagem e conhecimento (SEVERO, 2015). Ensejando superar a ausência de saberes específicos na relação entre ensino e aprendizagem, resultando em uma diminuição de reflexão, por parte dos professores, sobre as suas práticas pedagógicas e sobre a qualidade do ensino, nas diversas esferas em que essa atividade ocorre (TRINDADE et al., 2017).

As alterações nas políticas econômicas e sociais ocasionadas pela reorganização do capital, influenciam fortemente a organização geral da sociedade, e como a escola é uma instituição social, ela também necessitará de uma reorganização de sua estrutura, inclusive no âmbito da gestão escolar (Carvalho, 2012; Vieira, 2008). Se a própria escola é afetada pelas mudanças que ocorrem na sociedade, as instituições não escolares acolhem essas mudanças de forma mais rápida ainda, o que leva aos profissionais que atuam nesses locais sentirem a necessidade de aplicar a gestão nos espaços que atuam, privilegiando os saberes da gestão, esses saberes se conectaram com outros diversos dentre eles o de elaboração de projetos socioeducativos que permitirão ao pedagogo uma visão mais ampla para construção de estratégias com finalidades formativas (SEVERO, 2015).

Os projetos socioeducativos são ações que integram educação e proteção social, que permitam a formação da cidadania (ZUCCHETTI; MENEZES, 2010), além desse campo, também tem sido utilizada a (re)qualificação de jovens e adultos desempregados ou subempregados que necessitam de experiência de trabalho coletivo (ZUCCHETTI; MOURA, 2010). Com o domínio desse saber, o pedagogo poderá desenvolver o exercício da liderança organizacional e condução grupal, que possivelmente se ampliará através das experiências de formação permanente e continuada exercidas durante o contexto sócio-ocupacional vivenciado pelo profissional (SEVERO, 2015).

A construção dos saberes citados anteriormente, depende do desenvolvimento de habilidades, essas devem ser entendidas como: as aprendizagens provocadas intencionalmente que permitem 0 domínio e desempenho de ações que se associam a um determinado leque de atividades humanas (SEVERO, 2015, p. 217-218). As habilidades são necessárias para que o pedagogo desempenhe suas funções diante das transformações contemporâneas, enfocando o desenvolvimento humano, o trabalho em equipe, o aprofundamento teórico, estudando os processos de aprendizagem, as estratégias de ensino 
(NASCIMENTO et al., 2010). Na Tabela 1 (Anexo A), pode-se encontrar a lista com habilidades de cunho intelectual, operacional e socioafetiva, resultados de um levantamento feito com professores que atuam em espaços não escolares por SEVERO (2015).

\section{CONSIDERAÇÕES FINAIS}

O presente levantamento desvelou as necessidades formativas necessárias para atuação dos profissionais pedagogos tanto em âmbito das organizações não escolares quanto de instituições escolares, as necessidades estão no campo dos diversos saberes que fundamentam os processos educativos e que precisam do suporte de diversas habilidades no aspecto intelectual, operacional e socioafetivo.

Um problema recorrente é a falta de conhecimento do público em geral (donos de empresas, professores, civis etc) em relação a possibilidade de atuação do pedagogo em espaços não-escolares. A figura deste é vista apenas como um professor de educação infantil e fundamental I. Devido a esse desconhecimento, o pedagogo acaba por se limitar apenas a escolas, o que se revela um ponto negativo, pois por meio de sua formação pode auxiliar a sociedade como um todo em outras esferas sociais.

Percebe-se ainda que, em empresas privadas, ONG's, hospitais (espaços não-escolares), não há a presença de pedagogos ou há de forma tímida, o que pode se considerar uma falha das instituições, levando em conta a importância desse profissional, conforme a discussão presente nesse trabalho, para o desenvolvimento desses locais.

O poder público deve abrir mais espaço para a atuação do pedagogo nas mais diversas instituições, destinando vagas de concursos públicos e até mesmo criando leis que obriguem a contratação desses profissionais em empresas privadas dos mais diversos segmentos, dando mais visibilidade a essa profissão.

Nesse sentido, o presente estudo apontou para lacunas importantes que devem ser superadas tanto pelas instituições que oferecem formação inicial quanto a formação continuada, assim como pode servir como instrumento de informação e construção do conhecimento para os profissionais pedagogos que tem por objetivo atuarem nas mais diversas organizações não escolares. 


\section{REFERÊNCIAS}

AQUINO, S. L.; SARAIVA, A. C. L. C.; BRAÚNA, R. C. A. Representações sociais da atuação do pedagogo na saúde: saberes envolvidos e experiências compartilhadas. Interfaces da educação, v. 3, n. 7, p. 128-145, 2012.

ARANTES, A. P. P.; GEBRAN, R. A. O Curso de pedagogia e o processo de formação do pedagogo no Brasil: Percurso Historico E Marcos Legais. Holos, v. 30, n. 6, p. 280-295, 2014.

BARBOSA, A. H.; ABDIAN, G. Z. Gestão escolar e formação do pedagogo: relações e implicações a partir da análise de projetos político-pedagógicos de universidades públicas. Educação em Revista, v. 29, n. 4, p. 245-276, 2013.

BOGORNY, Q. L. DA S. Atuação dos pedagogos em universos não escolares. Revista Eventos Pedagógicos, v. 6, n. 2, p. 200-208, 2015.

BRANDÃO, C. R. O que é educação. São Paulo: Brasiliense, 2007.

BRASIL, C. N. D. E. Conselho Nacional de Educação Conselho Pleno Resolução CNE/CP N ${ }^{\circ}$ 1, DE 15 DE MAIO DE 2006. Diretrizes Curriculares para o curso de Pedagogia, Licenciatura., 2006.

CARVALHO, E. J. G. DE. Gestão escolar : da centralização à descentralização. Cadernos de Pesquisa em Educação - PPGE/UFES, v. 18, n. 36, p. 33-53, 2012.

COSTA, J. J. S. A Educação Segundo Paulo Freire : Uma Primeira Análise Filosófica the Educat. Theoria, v. 7, n. 18, p. 72-88, 2015.

CRUZ, G. B. DA. Curso de pedagogia no Brasil: história e formação com pedagogos primordiais. Cadernos de Pesquisa, v. 42, n. 145, p. 311-316, 2012.

FERREIRA, N. S. C. Diretrizes curriculares para o curso de Pedagogia no Brasil: a gestão da educação como gérmen da formação. Educação e Sociedade, v. 27, n. 97, p. 1341-1358, 2006.

FIGUEIREDO, A. D. A Pedagogia dos contextos de aprendizagem. E-curriculum, v. 14, n. 3, p. 809-836, 2016.

FIORIN, B. P. A.; FERREIRA, L. S. O curso de pedagogia no brasil: história e influência para o trabalho dos pedagogos. Revista reflexão e Ação, v. 21, p. 44-65, 2013. 
FREIRE, P. Pedagogia da Autonomia: saberes necessários à prática educativa. São Paulo: Paz e Terra, 1996.

GUIRALDELLI JUNIOR, P. O que é Pedagogia. 4. ed. São Paulo: Brasiliense, 2007.

GOHN, M. D. G. Educação não-formal, participação da sociedade civil e estruturas colegiadas nas escolas. Ensaio: Avaliação e Políticas Públicas em Educação, v. 14, n. 50, p. 27-38, 2006.

JACOBUCCI, D. F. C.; FERREIRA, F. H. N.; SANTANA, F. R. Representações de educação não formal e utilização do espaço museal por professoras do ensino fundamental. Ensino Em Re-Vista, v. 20, n. 1, p. 125-132, 2013.

KIRSCH, D. B.; SOFFNER, R. K. Formação do professor pesquisador: a importância da fundamentação epistemológica das dissertações. Revista lberoAmericana de Estudos em Educação, v. 10, n. 1, p. 246-258, 2015.

LEFF, E. Saber ambiental: sustentabilidade, racionalidade, complexidade, poder. 6 . ed. Petrópolis: Vozes, 2008.

LEMOS, ILANE BARBOSA; CABRAL, C. L. D. O. O pedagogo e os campos de atuação não escolar: desafios/dificuldades para inserção desse profissional. Revista Fundamentos, v. 2, n. 2, 2015.

LIBÂNEO, J. C. Tendências pedagógicas na prática escolar. Revista ANDE, n. 6 , p. 1-35, 1982.

A pedagogia em questão : entrevista com José Carlos Libâneo. Olhar de professor, v. 10, n. 1, p. 11-33, 2007.

MENDES, L.; FILHO, D. F.; VIDAL, D. G. Os tempos e os espaços escolares no processo de institucionalização da escola primária no Brasil. Revista Brasileria de Educacao, n. 14, p. 19-35, 2000.

MOURA, E. P. G.; ZUCCHETTI, D. T. Socialização escolar, educação não escolar e (Con)formação de sujeitos. Revista Contrapontos, v. 14, n. 2, p. 339, 2014.

NASCIMENTO, A. S. et al. A atuação do pedagogo em espaços não escolares: desafios e possibilidades. Pedagogia em Ação, v. 2, n. 1, p. 61-65, 2010.

OLIVEIRA, R. N. M.; LIMA, M. G. S. B. Formação de professores como práxis: princípios e práticas. In: CABRAL, C. L. O. et al. A professoralidade e as práticas da docência: identidade, saberes e desenvolvimento profissional. Teresina: EDUFPI, 
2016. $245 p$.

PENNA, M. G. DE O. Aspectos da prática docente : formação do professor e processos de socialização. Educação: Teoria e Prática, v. 22, n. 39, p. 38-55, 2012.

PRADO, A. A.; MACHADO, E.; CARDOSO, M. A. B. DA S. A atuação do pedagogo na empresa : a aplicação Eficiente e Eficaz da Pedagogia Empresarial. Educação, Cultura e Comunicação, v. 4, n. 7, p. 63-78, 2013.

REIS, L. G. Produção de monografia da teoria a prática: o método educar pela pesquisa (MEP), 4 ed. Brasília: SENAC-DF, 2012.

RODRIGUES, J. DE A. et al. Tendências Pedagógicas: conflitos, Desafios e Perspectivas de Docentes de Enfermagem. Revista Brasileira de Educação Médica, v. 37, n. 3, p. 333-349, 2013.

SANTOS, VANESSA SILVA; SANTOS, V. L. F. DOS. A atuação do pedagogo na educação não-formal: quais possibilidades de intervenção profissional? Interfaces da educação, v. 2, n. 5, p. 118-127, 2011.

SANTOS, S. S. DOS S. S. S. DOS; GUIMARÃES, L. T. O pedagogo e os espaços educativos não formais: conhecendo as organizações não governamentais (ongs) de Paranaíba - MS. ANAIS DO SEMINÁRIO EM EDUCAÇÃO E COLÓQUIO DE PESQUISA, v. 1, n. 10, p. 161-174, 2015.

SCHEIBE, L. Diretrizes curriculares para o curso de pedagogia: trajetória longa e inconclusa. Cadernos de Pesquisa, v. 37, n. 130, p. 43-62, 2007.

SEVERO, J. L. R. DE L. Pedagogia e educação não escolar no brasil : crítica epistemológica, formativa e profissional. [s.l: s.n.].

STRECK, D. R. Qual o conhecimento que importa? Desafios para o currículo. Currículo sem Fronteiras, v. 12, n. 3, p. 8-24, 2012.

TRINDADE, R. A. DA et al. Docentes de cursos da área da saude: o papel da didatica na fronteira profissao/professor. Roteiro, v. 42, n. 1, p. 133, 2017.

VIANA, C. E. Educomunicação nos processos educativos. VI Educom e EducomSul. Anais...2015

VIEIRA, K. A. L. Gestão escolar : os parâmetros sócio-antropológicos. Revista online de Política e Gestão Educacional, n. 5, p. 1-17, 2008.

ZUCCHETTI, D. T.; MENEZES, M. M. DE. Projetos socioeducativos. A 
naturalização da exclusão nos discursos de educadores. Revista Sociedade e Estado, v. 25, n. 3, p. 465-478, 2010.

ZUCCHETTI, D. T.; MOURA, E. P. G. DE. Práticas socioeducativas e formação de educadores: novos desafios no campo social. Ensaio: Avaliação e Políticas Públicas em Educação, v. 18, n. 66, p. 9-28, 2010.

ANEXO A- Tabela com habilidades intelectuais, operacionais e socioafetivas necessárias aos saberes pedagógicos para atuação em atividades educativas não escolares.

\section{HABILIDADES INTELECTUAIS}

Diagnosticar necessidades formativas para o desenvolvimento pessoal

Conhecer diferentes estilos de aprendizagem

Criar parâmetros de qualidade para ações educativas e processos de aprendizagem

Identificar problemáticas educativas no desenvolvimento de processos institucionais diversos

Vislumbrar iniciativas para o desenvolvimento sócio-comunitário

Refletir criticamente sobre situações educativas

\section{HABILIDADES OPERACIONAIS}

Elaborar planos, programas, projetos e ações adaptados a diversas necessidades formativas

Desenvolver instrumentos e técnicas para promover a integração e participação coletiva

Aplicar e coordenar processos educativos de desenvolvimento social, organizacional e profissional

Supervisionar centros, unidades, serviços, recursos e organismos educativos de natureza não escolar

Avaliar planos, programas e projetos socioeducativos de natureza não escolar

Avaliar processos de aprendizagem e agentes educativos

Desenvolver meios e recursos de inovação educativa

Utilizar tecnologias da comunicação e informação para gestão, execução e avaliação de processos não escolares

Assessorar grupos marginalizados em processo de desenvolvimento socioeducativo 


\section{HABILIDADES SOCIOAFETIVAS}

Reconhecer e apoiar a diversidade

Trabalhar em equipe

Exercer a liderança e formar líderes

Manter e fomentar o diálogo entre as pessoas

Mediar a resolução de conflitos interpessoais

Manter atitudes proativas no contexto de trabalho

Estabelecer vínculos empáticos

Manter um bom nível de comunicação

Fonte: Severo (2015). 